
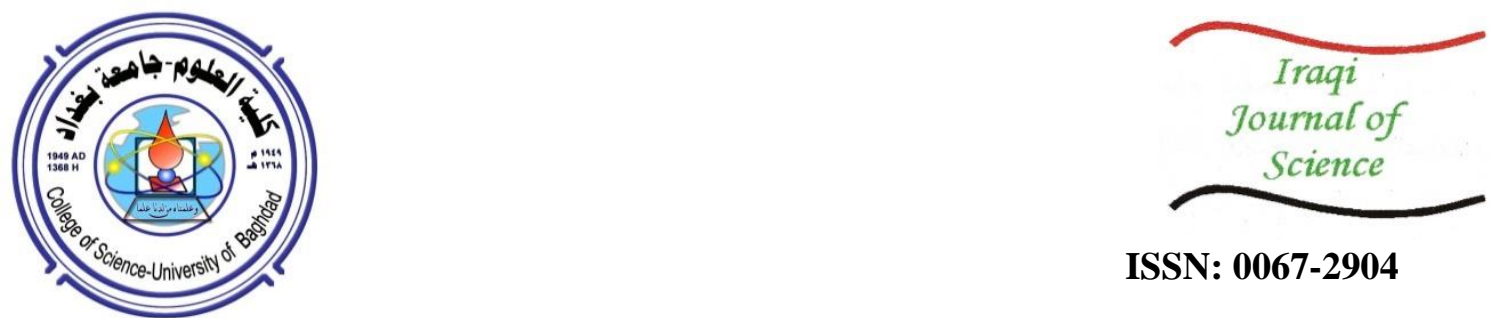

ISSN: 0067-2904

\title{
Image Georeferencing using Artificial Neural Network Compared with Classical Methods
}

\author{
Zahraa Ezzulddin Hussein \\ Surveying Engineering, College of Engineering, University of Baghdad, Baghdad, Iraq
}

Received: 17/12/2020

Accepted: 25/2/2021

\begin{abstract}
Georeferencing process is one of the most important prerequisites for various geomatics applications; for example, photogrammetry, laser scan analysis, remotely sensing, spatial and descriptive data collection, and others. Georeferencing mostly involves the transformation of coordinates obtained from images that are inhomogeneous due to accuracy differences. The georeferencing depends on image resolution and accuracy level of measurements of reference points ground coordinates. Accordingly, this study discusses the subject of coordinate's transformation from the image to the global coordinates system (WGS84) to find a suitable method that provides more accurate results. In this study, the Artificial Neural Network (ANN) method was applied, in addition to several numerical methods, namely the Affine divided difference, Newton's divided difference, and polynomial transformation. The four methods were modelled and coded using Matlab programming language based on an image captured from Google Earth. The image was used to determine reference points within the study area (University of Baghdad campus). The findings of this study showed that the ANN enhanced the results by about $50 \%$ in terms of accuracy and $90 \%$ in terms of homogeneity, compared with the other methods.
\end{abstract}

Keywords: Coordinates, Neural Network, Affine, georeferencing, transformation.

\section{الإسناد الجغرافي للصورة باستخدام الثبكات العصبية الاصطناعية مقارنة بالطرق التقليدية}

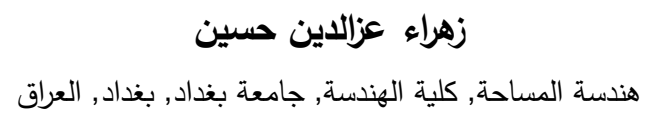

(الخلاصة

تعتبر عملية الإسناد الجغرافي واحدة من أهم المهام التي تعد مطلباً أساسياً للعديد من تطبيقات الجيوماتكس.

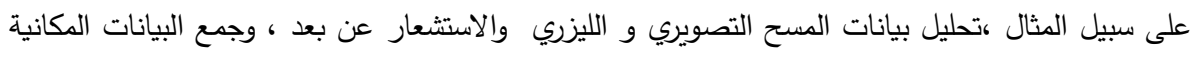

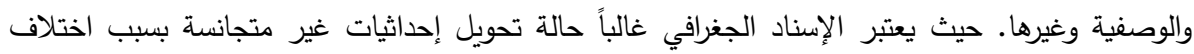

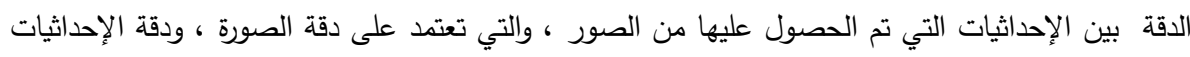

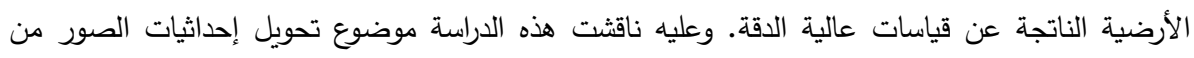

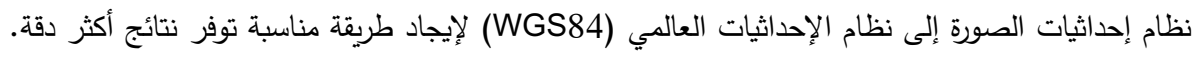

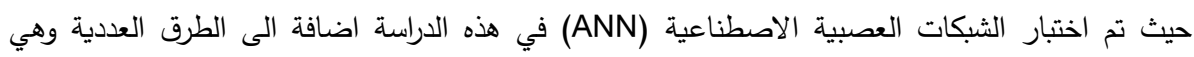

\footnotetext{
*Email: zahraa_azeldeen@coeng.uobaghdad.edu.iq
} 


$$
\begin{aligned}
& \text { طريقة Affine و اختلاف نيوتن المقسم (Newton divided difference) والتحول متعدد الحدود. كما تمت } \\
& \text { عملية بناء النموذج الرياضي والترميز للطرق الأربعة باستخدام لغة البرمجة Matlab اعتمادا على عدد معين } \\
& \text { من النقاط المرجعية التي حددت مواقعها باستخدام صور الـ Google Earth داخل منطقة الدراسة (حرم }
\end{aligned}
$$

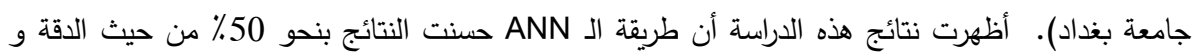

$$
\begin{aligned}
& \text { 90 فيما يتعلق بالتجانس مقارنة بالطرق الأخرى. }
\end{aligned}
$$

\section{Introduction}

The coordinates system is the basis for determining the location or direction of an object in the earth, space or sea, relative to a certain origin, which is the significance of geometrics science [1]. Additionally, the development of a global coordinates system based on the World Geodetic System (WGS), which represents a standard system to the earth, has a significant role in collecting various data of different sources in a real unified coordinates system [2]. Accordingly, such a system enables performing actual computations and analyses that mimic the real surface of the earth, depending on any available source of spatial information. Thus, WGS84, which is the most recent version of the system, is a major reference for use in geodesy, cartography, and space navigation techniques, including GPS [3]. Often, we use a local system to collect data in a field or a tool system, so- called screen system, to collect and interpret data from images. This leads to the necessity of finding the appropriate way to integrate and convert the coordinates from separate systems to a uniform global system [4]. There are several methods to achieve the transformation, but the selection of one particular method is based on the aim of the transformation and the available number of common points known in both systems [5]. Generally, Affine, Helmert, and the projective methods are widely used, which are based on the elements of transformation mathematical models that include scale, rotation, and translation parameters. These traditional methods lack uniform transformation achievements due to insufficient accuracy [6]. Numerical methods have been also exploited in this problem. Recently, the optimization and artificial intelligence methods play an important role in coordinates transformation techniques. These methods are based on the estimation of the best solution rather than mathematical models. For instance, the ANN, which is one of the artificial intelligence methods, has been adopted by several researches in recent days. The mechanism of ANN is based on an optimal solution to find the best result. Hence, it does not need to compute the rotation and translation parameters, in addition to the scale value for the transformation problem. Rather, it depends on best fitting solutions to reach the optimum values [7]. As any new strategy, ANN was tested by many studies to investigate its efficiency in coordinate's transformation issues. For instance, the efficiency of ANN was examined in the problem of coordinate's transformation between the coordinates system of GPS (WGS84) and the Hungarian national reference system (EOV). The findings were compared with the polynomial transformation model, which is based on two different sizes of database; these are 43 and 1153 points, respectively. The best results were obtained with ANN rather than the polynomial method when a huge database was used [6]. In another study, a back propagation artificial neural network (BPANN) was evaluated for the issue of 3D coordinates transformation procedure for the two reference systems of the Turkish national geodetic network. These systems are the European Datum 1950 (ED50) and the WGS84 of the Turkish national fundamental GPS network (TNFGN). The results of BPANN were compared with the seven-parameter similarity transformation method (MolodenskyBadekas). The BPANN was recommended for the efficient use of the 3D transformation due to its more accurate results than Molodensky-Badekas method [8]. Subsequently, three types of ANN were tested for 2D coordinates transformation; these are Cascade Forward Back Propagation (CFBP), Radial Basis Function Neural Network (RBFNN), and Feed Forward Back Propagation (FFBP). Regarding the coordinates systems used in Turkey, the 2D 
transformations were applied from the European Datum 1950 (ED50) and International Terrestrial Reference Frame 1996 (ITRF96) coordinate systems, based on three datasets of the study area (the city of Trabzon). The results indicated the ability to use the ANN algorithms for 2D transformation, with the best solution achieved when optimum parameters are selected [9]. Moreover, a novel 3D geodetic datum transformation was presented for the Egyptian geodetic network from global to local coordinates using the ANN technique. Traditional transformation models, which are Molodensky, Helmert, and the numerical method, represented by minimum curvature surface and regression, were compared with the ANN technique. The results showed that the coordinates resulted by ANN transformation were improved in space directions by 37 to $72 \%$ [10]. On the other hand, an analytical study clearly demonstrated that the neural networks (NNs) are indeed ultimately polynomial regression (PR). Accordingly, various types of data were exploited in experiments related to this study. In all cases, the results showed that the PR gave similar accuracy to that given by NNs, or even higher in some cases [11]. Regarding this study, the results indicated that the ANN method is more accurate and homogeneous for the purpose of the transformation of coordinates from an image system (tool system) to a global system.

\section{Artificial Neural Network Concept}

An ANN represents a mathematical model of a living nervous system. Generally, ANN consists of two main components that include the processing elements and the connections among them [12]. The processing elements are namely neurons that are known in ANN as nodes, whereas the connection elements are called links. Each link is characterized by a weight parameter that is correlated with it. It is worth to mention that ANN processes a group of information in a way inspired by the biological neural networks. Consequently, an input data (signals) are transmitted by weighted links to the neuron, which in turn multiplies the input data by the weight value to produce output data by a nonlinear relation. ANN has the ability, by continuous training, to find or teach the relation that is connecting the input with output data $[13,14]$. The benefit of ANN is reaching solutions without to the need for any algorithmic or mathematic model. The ANNs are different in their structure depending on the various methods they utilize to process and connect the neurons. Mainly, ANN can be trained by utilizing two methods, which are the supervised (A back propagation) and unsupervised (forward propagation) methods. In this study, the back propagation method of ANN was considered due to the fact that it was recommended by several researches $[15,16]$. In general, the mathematical model of ANN can be written in a simple way as shown in Eq. (1) $[17,18]$.

$$
f(x)=\varphi\left(\sum_{i=1}^{n} w_{i} x_{i}+b\right)
$$

where $\mathrm{w}$ denotes the weights vector, $\mathrm{x}$ denotes the inputs vector, $\mathrm{b}$ denotes the bias, and $\varphi$ denotes the activation function in a non-linear case.

\section{The Numerical Methods}

The numerical methods can be employed to solve the coordinate's transformation problem. Mainly, the numerical method is based on an interpolation process to estimate a dependent variable value in relation to an independent variable value that is located between its two drastic values [19]. In this study, the methods of Newton's divided difference and polynomial transformation were used and can be illustrated as follows:

a- The Newton's divided difference is an interpolation polynomial method that fits a certain set of points. The Newton's method is, generally, divided into four types; Newton's forward, Newton's backward, Newton's divided difference, and Newton's central difference interpolation [20]. Based on previous recommendation of researches, the Newton's Divided Difference method, based on the divided difference equation, was taken into consideration [21]: 


$$
f\left(x_{0}, x_{1}, x_{2} \ldots x_{n}\right)=\frac{f\left(x_{1}, x_{2}, x_{3} \ldots x_{n}\right)-f\left(x_{0}, x_{1}, x_{2} \ldots x_{n-1}\right)}{x_{n}-x_{0}}
$$

The $\mathrm{n}^{\text {th }}$ degree interpolation polynomial for The Newton's divided difference can be written as:

$$
\begin{aligned}
f(x)= & f\left(x_{0}\right)+\left(x-x_{0}\right) f\left[x_{0}, x_{1}\right]+\left(x-x_{0}\right)\left(x-x_{1}\right) f\left[x_{0}, x_{1}, x_{2}\right] \\
& +\ldots+\left(x-x_{0}\right)\left(x-x_{1}\right) \ldots\left(x-x_{n-1}\right) f\left[x_{0}, x_{1}, \ldots, x_{n}\right]
\end{aligned}
$$

For more information about the mathematical model of the Newton's divided difference, see [22-24].

b- The polynomial transformation is a common numerical method exploited to convert the coordinates from one system to another. The polynomial method consists of different numbers of terms depending on the order of polynomial [25]. It is a nonlinear method which includes a myriad of polynomial terms. The first order of the polynomial (ignoring all higher ranks) is called the Affine transformation, which is based on rotation, scaling, and translation [26]. The polynomial transformation formula can be summarized in Eq. 4 and 5 [27].

$$
\begin{gathered}
X_{2}=a_{0}+a_{1} x_{1}+a_{2} y_{1}+a_{3} x_{1} y_{1}+a_{4} x_{1}^{2}+a_{5} y_{1}^{2}+\cdots \\
Y_{2}=b_{0}+b_{1} x_{1}+b_{2} y_{1}+b_{3} x_{1} y_{1}+b_{4} x_{1}^{2}+b_{5} y_{1}^{2}+\cdots
\end{gathered}
$$

where $a_{0}, a_{1} \ldots a_{5} \ldots \ldots b_{0}, b_{1} \ldots b_{5}$ represent the parameters that can be estimated using linear simultaneous equations or by least squares adjustment methods, and $\mathrm{X}_{2}, \mathrm{Y}_{2}, \mathrm{X}_{1}, \mathrm{y}_{1}$ are the coordinates in the two different systems.

\section{Methods, Experiments, and Evaluation}

The methodology of this study consists mainly of two phases: the fieldwork and the office work, which can be explained as follows:

\subsection{Fieldwork (Data Collection)}

The fieldwork included reconnaissance and measurements within the study area, which is the University of Baghdad campus, Baghdad, central Iraq. Generally, any georeferencing (transformation) process needs reference points that are known in different coordinate systems in order to connect them. Accordingly, the reconnaissance step included initially the determination of the reference point locations, taking into consideration the ability to clearly distinguish them in the satellite images using the Google earth data source with sub-meters resolution. Thus, the reference points were distributed over the study area within approximately one square kilometer size from its center (see Figure 1), covered by about sixty points. In the measurement step, the reference points located on the ground (intersection of roads and rims) were observed using the static GNSS technique, which included two hours of occupation time using Topcon-GR5 receivers type, for providing locations referenced to the global coordinates system (WGS84). While, the reference points determined on buildings' corners were observed utilizing a total station device, depending on the global coordinates system resulted from the ground reference points. It is worth to mention that fifty points of the reference points were used for transformation process (transformation points), while the others (ten points) were adopted as check points for accuracy assessment purpose. 


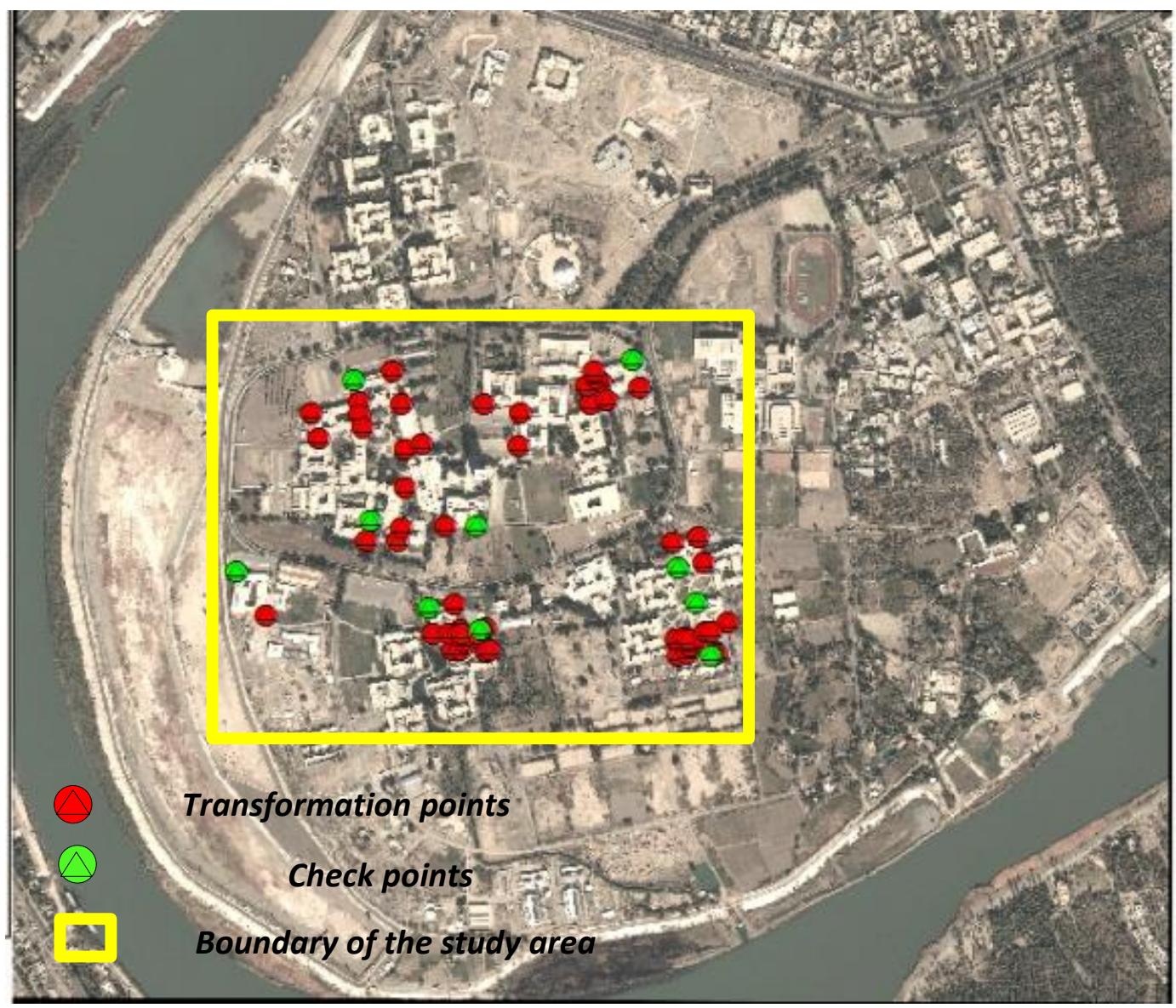

Figure 1-Distribution of the reference points over the study area (University of Baghdad Campus).

\subsection{Office Work}

Modeling is the first part of the office work of this study for comparing the coordinates transformation methods. The second part involves accuracy level assessment. Firstly, Google earth image of the study area was imported to ArcGIS software. Then, tool coordinates (screen coordinates) for observed in the fieldwork were exploited in the transformation process. Thus, all transformation methods were modeled utilizing Matlab R2017b programming language, as explained in the following section.

\subsubsection{The ANN method}

The structure of ANN was built up based on the trial and error method. The structure was created starting from one hidden layer and two neurons, using a variety of mathematical functions, also called transfer functions. Three types of transfer functions are often used in the ANN method, which are purelin, hardlim and logsig functions. These functions and their corresponding equations are illustrated in Figure 2. The output layers were computed from the results of the mathematical function of the hidden layer, which is the mid layer that allows the information to flow through it reaching the output layer, as illustrated in Eq. (1). The latter was processed based on both the weight (w) and bias (b) values, starting from the random values generated by Matlab. After that, the number of hidden layers and neurons were gradually increased, seeking for the least error that can be obtained. Accordingly, the best 
structure resulted from this study was found to consist of two hidden layers with the logsig function and three neurons for each layer, as shown in Figure 2.

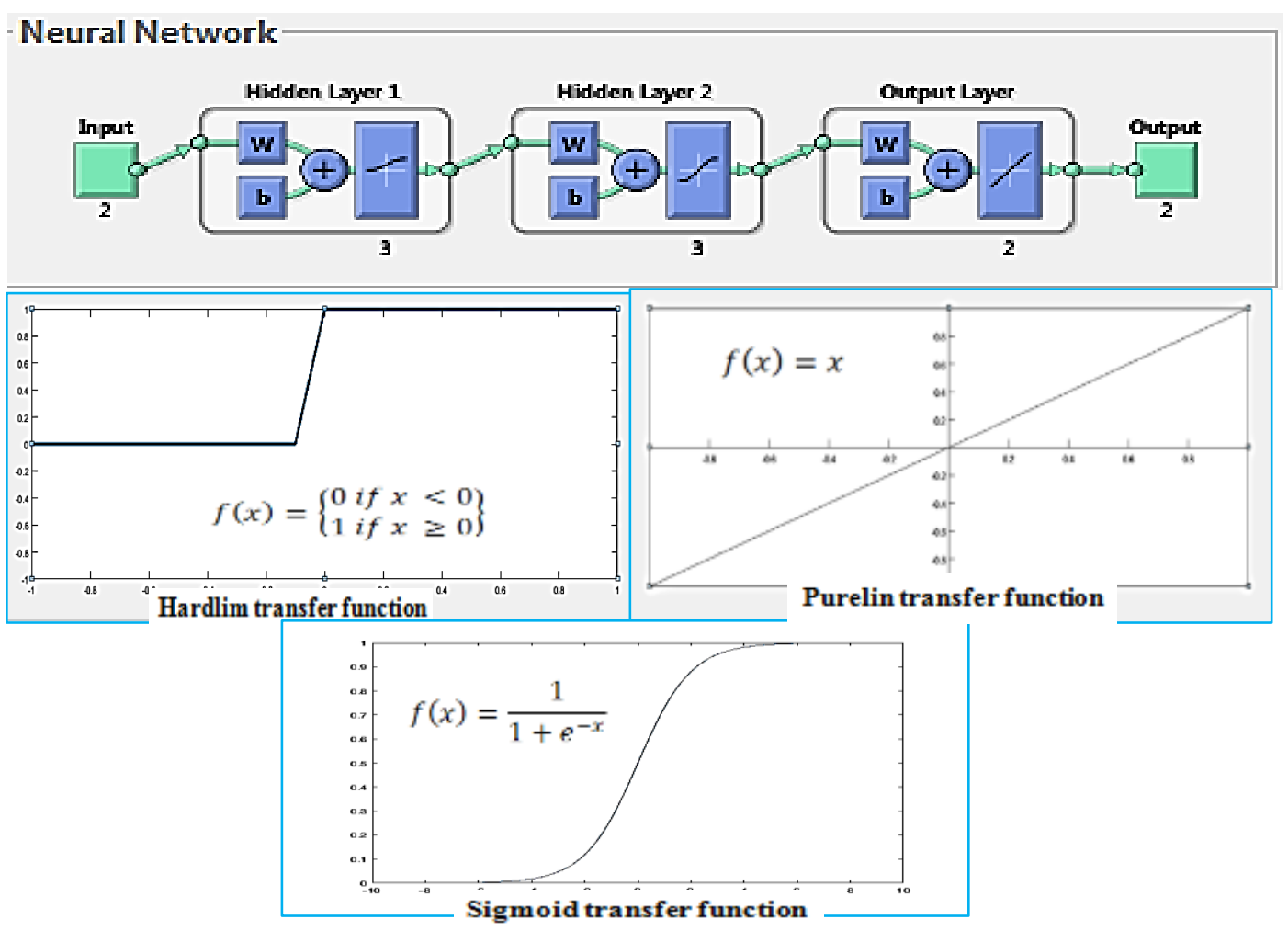

Figure 2-The Structure of ANN built in Matlab programming language.

By using experimental method of this study, it was noted that the number of points used in the ANN method plays an important role in changing the accuracy level obtained from the results. Thus, increasing the number of points and distributing them homogeneously over the study area clearly increased the accuracy of the results. Accordingly, all reference points (fifty points) were used in the training case of the ANN method, with enormous values of iterations that reached to about one thousand. The values of the RMSEs, resulting from the differences between the check points and the coordinates transferred from the ANN method, were 1.508 and 1.727 meters in $\mathrm{X}$ and $\mathrm{Y}$ directions, respectively. The values of differences between the observed global coordinates of the check points and the global coordinates, computed for the same points by the ANN transformation method, are summarized in Figure 3. 


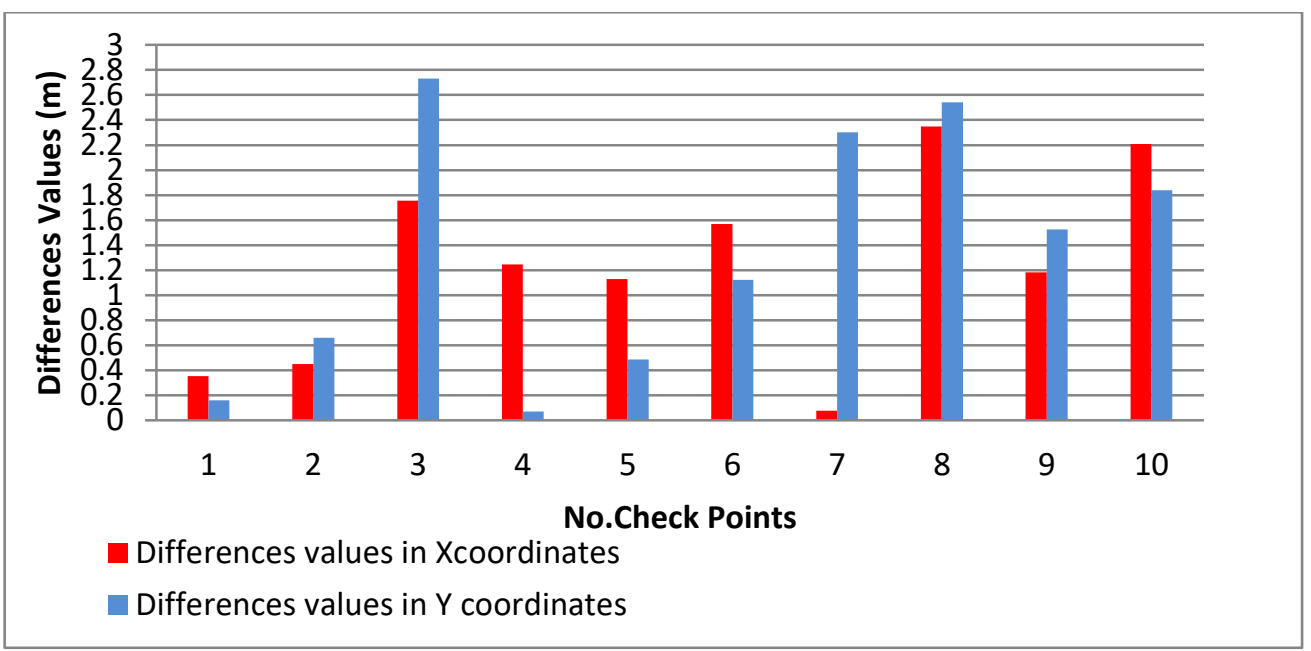

Figure -3 Values of differences of two dimensional coordinates related to the ANN Method.

\subsubsection{Modeling of numerical methods}

a. Affine transformation method

As known, the 2D Affine transformation method is derived from the polynomial formula and represents the first order of polynomial that has 6 parameters, as shown in Eq. 4 and 5 . The Affine formula needs a minimum of three points to solve it. For more details of Affine transformation method, it is worth to see $[28,29]$. Regarding the experimental work of the Affine transformation, the fifty reference points were used to compute the six parameters of the Affine method. The least squares adjustment method was used for best fitting the redundancy equations resulted from the fifty points, which produced two equations for each point. The results showed that the Affine method delivered bad accuracy with very high values of RMSE, reaching more than 30 meters in each the $\mathrm{X}$ and $\mathrm{Y}$ directions. The enormous error of the Affine transformation indicates that it is unsuitable for this study of transformation occurring between the tool coordinates system and the global system (WGS84).

b. Newton's divided difference and polynomial method

In this study, numerical interpolation methods were utilized to transform coordinates from the tool coordinates system to the global system (WGS84). The two numerical methods used are Newton's divided difference and polynomial transformation. Regarding the Newton's method, the divided difference values were coded and computed for modeling the Newton's formula, as explained in Eq. (2). Accordingly, the resulted divided differences were used in Eq. (3) to compute $X$ and Y directions. The number of the Newton's terms is based on the number of the known points allocated for use in this method. Regarding this study, the number of points used was increased gradually, starting from two points and reaching fifty points. Initially, two of the observed reference points were used and the accuracy level was then evaluated by the check points, which are known coordinates in the two systems. The resulting accuracy values of the two points used in Newton's equation were 4.784 meters in the $\mathrm{X}$ direction and 6.036 meters in the Y direction, as estimated based on the values of the RMSE. As the number of points used gradually increased, the mean error began to decrease markedly, reaching its lowest value of 3.202 meters (for the two directions) when using 10 points. It was also noted that increasing the number of points to higher than 10 points did not improve the accuracy or clearly reduce the value of the mean errors; this indicates reaching a stable state. The values of the differences between the observed and computed global coordinates for the check points are summarized in Figure 4 as average differences between $X$ and $\mathrm{Y}$ directions. 


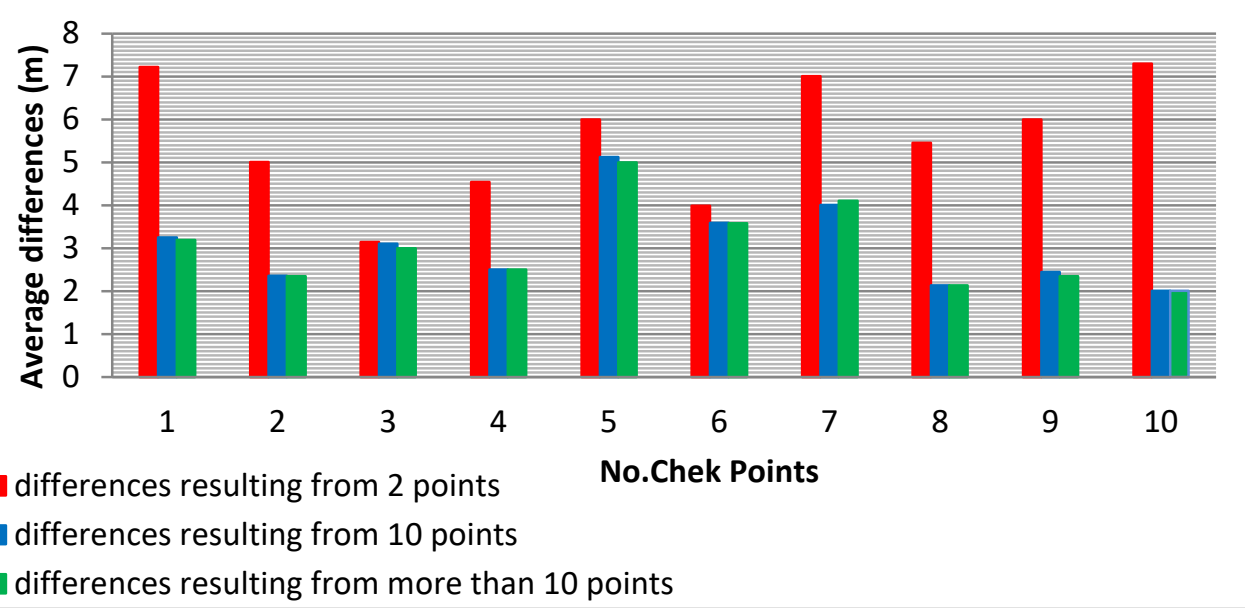

Figure $\mathbf{- 4}$ The values of differences depending on the number of points used in Newton's equations.

The colors of columns in Figure 4 refer to the values of differences related to the number of points exploited in Newton's Equations. Accordingly, it appears that the values of differences are highest when using 2 points, while they decrease when using 10 points. In addition, these values remain nearly constant when the number of points used in Newton's Equations exceeds 10 .

In the polynomial case of this study, second order equations with twelve parameters, as shown in Eq. 4 and 5, were considered based on experimental tests. Accordingly, 6 points were required to compute unknown parameters. All the 50 reference points were used to solve the polynomial equations. These required the least squares adjustment method to solve the redundancy in numbers of equations. The accuracy of the polynomial method was also indicated by the value of the RMSEs; these were 1.448 meter in the X direction and 5.575 meters in the $\mathrm{Y}$ direction, in relation to the check points. The values of differences between the observed and computed global coordinates of the check points are illustrated in Figure 5.

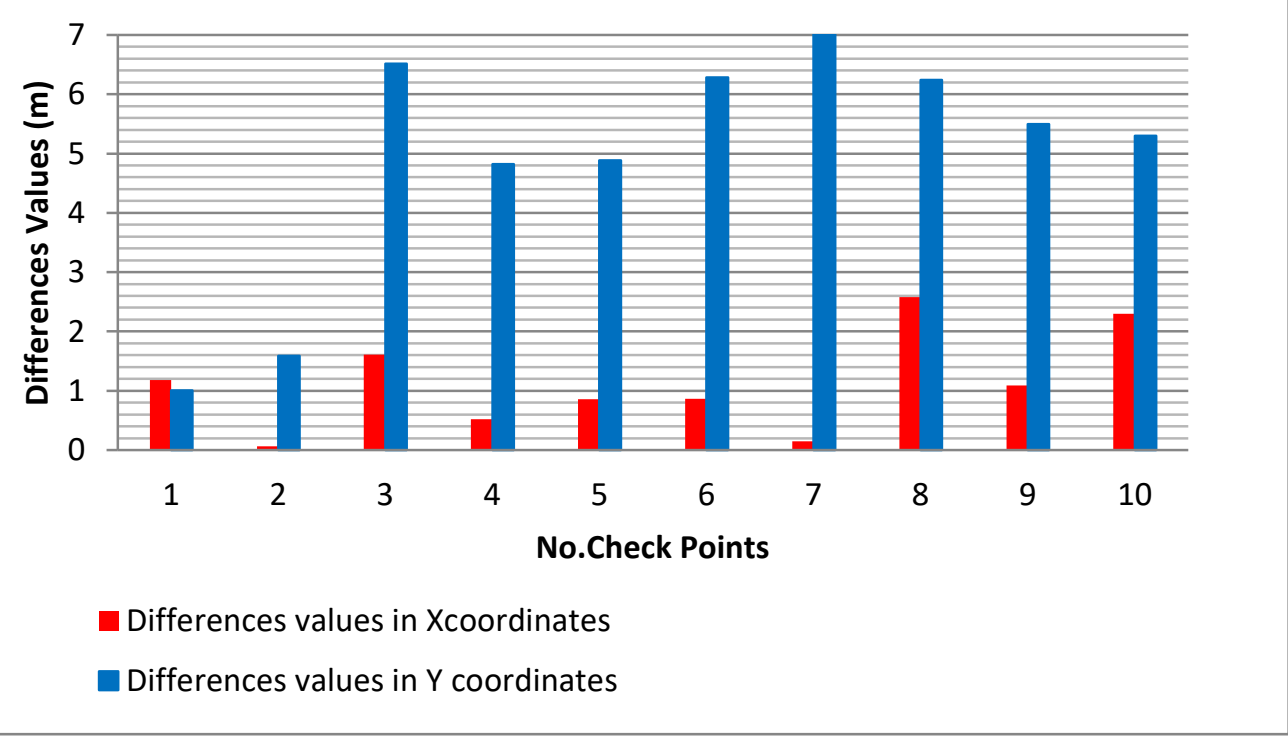

Figure 5 -The values of differences in the polynomial transformation method.

Finally, the main descriptive statistics for the four transformation methods are presented in Table 1. 
Table 1- The Descriptive Statistics of the Four Transformation Methods.

\begin{tabular}{|c|c|c|c|c|c|c|c|c|}
\hline \multirow[b]{2}{*}{$\begin{array}{l}\text { Statistical } \\
\text { Index }\end{array}$} & \multicolumn{2}{|c|}{ Neural } & \multicolumn{2}{|c|}{ Affine } & \multicolumn{2}{|c|}{ Newton } & \multicolumn{2}{|c|}{ Polynomial } \\
\hline & $\begin{array}{c}\text { Diff.X } \\
(\mathbf{m})\end{array}$ & $\begin{array}{c}\text { Diff. Y } \\
\text { (m) }\end{array}$ & $\begin{array}{l}\text { Diff. X } \\
\text { (m) }\end{array}$ & $\begin{array}{c}\text { Diff.Y } \\
(\mathbf{m})\end{array}$ & $\begin{array}{c}\text { Diff.X } \\
\text { (m) }\end{array}$ & $\begin{array}{c}\text { Diff. Y } \\
\text { (m) }\end{array}$ & $\begin{array}{c}\text { Diff.X } \\
(\mathbf{m})\end{array}$ & $\begin{array}{c}\text { Diff.Y } \\
\text { (m) }\end{array}$ \\
\hline Mean & 1.231 & 1.342 & 30.088 & 31.506 & 4.272 & 5.567 & 1.120 & 4.920 \\
\hline Minimum & 0.077 & 0.067 & 16.837 & 26.064 & 2.035 & 3.146 & 0.064 & 1.008 \\
\hline Median & 1.213 & 1.323 & 30.304 & 32.296 & 4.300 & 5.727 & 0.976 & 5.397 \\
\hline Maximum & 2.348 & 2.731 & 44.010 & 35.607 & 6.547 & 7.299 & 2.576 & 7.069 \\
\hline $\begin{array}{c}\text { Standard } \\
\text { Deviation }\end{array}$ & 0.768 & 0.991 & 7.805 & 3.329 & 1.412 & 2.103 & 0.838 & 2.046 \\
\hline
\end{tabular}

From the results presented in Table 1 and the values of RMSEs previously mentioned for the four transformation methods, it was found that the ANN transformation method is the most accurate and homogeneous in the case of transformation from the tool coordinates system to the global coordinates system. It is worth to mention that is transformation is inhomogeneous due to the fact that the accuracy of the tool coordinates depended on the resolution of the image, while the accuracy of global coordinates depended on the high accuracy of the terrestrial observations.

In this study, the tool coordinates based on the resolution of the Google earth image reached to an accuracy of about sub-meters, while the accuracy of the global coordinates reached to about millimeters, regarding the GNSS observations. However, it can be noticed that the ANN method improved the accuracy level of the results by $59 \%$ and $53 \%$, computed based on the percent relative error formula, compared with Newton's and polynomial methods, respectively. The results also showed that the Affine transformation gave very high error values that exceeded thirty meters. These were obtained from the experimental method. The very high RMSE value may be due to the fact that the accuracy difference between the data of the two systems (inhomogeneous case) creates a noise that needs an equation of a higher degree than the Affine method to reach an optimal equation that relates the two systems' data. This was proven when using the polynomial method, where the error was highly reduced, as presented in Table 1. Furthermore, the different accuracy between the two systems affected the results, not only in terms of accuracy, but even in terms of homogeneity. This can be noticed from the differences in standard deviation values between $\mathrm{X}$ and $\mathrm{Y}$ directions, ranging from a minimum value of $0.2 \mathrm{~m}$ using the ANN method to a maximum of $4.5 \mathrm{~m}$ obtained from the Affine and polynomial methods. This is equivalent to $90 \%$ improvement in homogeneity. Thus, these results indicate that the ANN transformation method is the most suitable for the inhomogeneous case of coordinate's transformation (different accuracy).

\section{Conclusions}

Although several methods for coordinate's transformation are available, the obtained accuracy level is not the same; it may also differ for the same method depending on several factors that include density and distribution of data within the study area, as well as differences in accuracy of data between the two systems. The study discussed the obtained results from an image georeferencing approach based on inconsistent coordinates transformation cases (i.e. accuracy differences) for converting coordinates from the tool to the global coordinates system (WGS84) using four methods, which are the ANN, Affine divided difference, Newton's divided difference and the polynomial methods. Fifty reference points were observed and included in the coordinate's transformation processes, in addition to ten check points exploited for accuracy assessment purposes. The reference and the check points were observed in the field, showing accuracy in millimeters based on the GNSS technique for providing the global coordinates system. In contrast, the accuracy of the tool coordinates system, using the same points, was near sub-meters level, based on the resolution of the Google Earth image. The findings of this study suggest that the accuracy of the two dimensional transformation of coordinates, resulted from the ANN method, is higher than that 
obtained from all the other methods used. This is due to the fact that the ANN showed significant enhancement in both the accuracy and homogeneity level compared with the other methods.

\section{Declaration of Conflict Of Interests}

I am pleased to declare that there is no conflict of interest regarding the article's content.

\section{References}

[1] A. M. AL-Hameedawi, "Comparing The Accuracy of Different Map Projections and Datums Using Truth Data", Journal of University of Babylon, Engineering Sciences, vol. 26, no. 4, pp.1232, 2018. https://www.journalofbabylon.com/index.php/JUBES/article/view/1063

[2] G. M. DAWOD, M. N. MIRZA, and K. A. AL-GHAMDI, "Simple Precise Coordinates Transformations for Geomatics Applications in Makkah Metropolitan Area", Saudi Arabia. Conference: FIG Working Week, pp. 1-10, 2011. https://www.google. iq/search?sxsrf= ALeKk 031cdY0-V6flDtX0E_wvwQ756WCaA\%3A

[3] D. Yuan, X. Cui, S. Wang, Y. Qiu, G. Wang, and J. Jin, " The Coordinate Transformation Method and Accuracy Analysis in GPS Measurement", International Conference on Environmental Science and Engineering, pp. 232 - 237, 2011. https://doi.org/10.1016/j.proenv.2012.01.271

[4] Y. Sisman,, "Coordinate transformation of cadastral maps using different adjustment methods", Journal of the Chinese Institute of Engineers, vol. 37, no. 7, pp. 869-882, 2014. https://doi.org/ $\underline{10.1080 / 02533839.2014 .888800}$

[5] B. Konakoğlu and E. Gökalp, "A Study on 2D similarity transformation using multilayer perceptron neural networks and a performance comparison with conventional and robust outlier detection methods", Acta Montanistica Slovaca, vol. 21, no. 4, pp. 324-332, 2016. https://www.researchgate.net/publication/311807933

[6] Zaletnyik, P., "COORDINATE TRANSFORMATION WITH NEURAL NETWORKS AND WITH POLYNOMIALS IN HUNGARY", International Symposium on Modern Technologies, Education and Professional Practice in Geodesy and Related Fields, Sofia, Bulgaria, pp. 471-479, 2005. https://www.semanticscholar.org/paper/coordinate-transformation-with-neural-networks

[7] Y. ZIGGAH, H. U. YOUJIAN, A. R. TIERRA, and P. M. LAARI, "Coordinate Transformation between Global and Local Data Based on Artificial Neural Network with K-Fold CrossValidation in Ghana", Earth Sci. Res. J, vol. 23, no. 1, pp.67-77, 2019. http://dx.doi.org/10.15446/esrj.v23n1.63860

[8] B. Turgut, "A back-propagation artificial neural network approach for three-dimensional coordinate transformation", Scientific Research and Essays, vol. 5, no. 21, pp. 3330-3335, 2010. https://www.researchgate.net/publication/229039359

[9] B. Konakoglu, L. Cakır and E. Gökalp, "2D COORDINATE TRANSFORMATION USING ARTIFICIAL NEURAL NETWORKS", International Archives of the Photogrammetry, Remote Sensing \& Spatial Information Sciences, vol. 42 (1/W1), pp.183-186, 2016. https://doi.org/ 10.5194/isprs-archives-XLII

[10] H. T. Elshambaky, M. R. Kaloop and J. W. Hu, "A novel three-direction datum transformation of geodetic coordinates for Egypt using artificial neural network approach", Arabian Journal of Geosciences, Vol. 11, No. 6, 2018. https://doi.org/ 10.1007/s12517-018-3441-6

[11] X. Cheng, B. Khomtchouk, N. Matloff, and P. Mohanty, "Polynomial Regression As an Alternative to Neural Nets". ArXiv, abs/1806.06850, 2018. https://www.google.iq/search

[12] E. P. Kumar and E. P. Sharma, "Artificial Neural Networks-A Study", International Journal of Emerging Engineering Research and Technology, vol. 2, no.2, pp. 143-148, 2014. http://www.ijeert.org

[13] H. Kukreja and Et all., "An Introduction To Artificial Neural Network", International Journal Of Advance Research And Innovative Ideas In Education, vo.1, no. 5, pp.2395-4396, 2016. https://www.researchgate.net/publication/319903816.

[14] A. I. Georgevici and M. Terblanche, "Neural networks and deep learning: a brief introduction", Intensive Care Med, vol. 45, pp. 712-714, 2019. https://doi.org/10.1007/s00134-019-05537-w 
[15] W. J. Park and J. B. Park, " History and application of artificial neural networks in dentistry", European journal of dentistry, vol. 12, no. 4, pp. 594-601, 2018. https://doi.org/10.4103/ejd.ejd_325_18

[16] J. Tan, N. NourEldeen,, K. Mao, J. Shi, Z. Li, T. Xu, and Z.Yuan, "Deep Learning Convolutional Neural Network for the Retrieval of Land Surface Temperature from AMSR2 Data in China", Sensors, 2019. https://doi:10.3390/s19132987

[17] E. S. Salami, M. Ehetshami, A. Karimi-Jashni, M. Salari, S. N. Sheibani, and A. Ehteshami, "A mathematical method and artificial neural network modeling to simulate osmosis membrane's performance", Modeling Earth Systems and Environment, vol. 2, pp.1-11, 2016. https://doi: 10.1007/s40808-016-0261-0

[18] I. C. Valim., A. M. Silva, A. V. Grillo, and B. F. Santos, "Development of Mathematical Model Based on Artificial Neural Network to Predict Density in Polymerization Process of Styrene", Chemical Engineering Transactions, vol. 74, pp. 751-756, 2019. https://doi.org/10.3303/CET1974126

[19] R. K. Gupta, "Numerical Methods: Fundamentals and Applications", Cambridge University Press, $2019 . \quad$ https://www.amazon.com/Numerical-Methods-Rajesh-Kumar-Guptaebook/dp/B07SKBR1KP

[20] B. Das, and D. Chakrabarty, "Newton's Divided Difference Interpolation formula: Representation of Numerical Data by a Polynomial curve", International Journal of Mathematics Trends and Technology (IJMTT), vol. 35, no.3, pp.197-203, 2016. https://doi:10.14445/22315373/IJMTTV35P528

[21] A. S. Shamloo and P. Hajagharezalou, "Interval Interpolation by Newton's Divided Differences", Journal of mathematics and computer science, vol. 13, pp. 231-237, 2014. http://www.isrpublications.com/jmcs/792/download-interval-interpolation-by-newtons-divided-differences

[22] D. R Neupane, "Estimation of Errors in Newton's Divided Difference Formula for Polynomial Interpolation of Functions x1/2, x1/3 and x1/4 in the interval [1, 2]", Journal of Chemical, Biological and Physical Sciences, vol. 6, no.1, pp. 324-343, 2016. https://www.jcbsc.org

[23] M. V. J and S. A, (2018) "Newton's Divided Difference Interpolating Polynomial Approach for Multi-choice Indefinite Quadratic Transportation Problem", International Journal of Pure and Applied Mathematics, vol. 118, no. 6, pp. 243-251, 2018. http://www.ijpam.eu

[24] R. P. Regmi, "Finding of principle square root of a real number by using interpolation method", Janapriya Journal of Interdisciplinary Research, vol.7, no.1, pp.77-83, 2018. https://doi.org/10.3126/jjis.v7i1.23053

[25] D. Varsamis, N. Karampetakis and P. Mastorocostas, "Transformations between Two-Variable Polynomial Bases with Applications", Applied Mathematics \& Information Sciences, vol. 10, no. 4, pp.1303-1311, 2016. http://dx.doi.org/10.18576/amis/100409

[26] A. Mierzejowska, and M. Pomykoł, "Calibration of raster image using GIS class softwareaccuracy analysis", IOP Conf. Series: Earth and Environmental Science, Vol. 261, 2019. https://doi:10.1088/1755-1315/261/1/012033

[27] D. Ampatzidis and S. A. Melachroinos, "The connection of an old geodetic datum with a new one using Least Squares Collocation: The Greek case", Contributions to Geophysics and Geodesy, vol. 47, pp. 39-51, 2017. https://doi.org/10.1515/congeo-2017-0003

[28] S. Kaji and H. Ochiai, "A concise parametrization of affine transformation", SIAM Journal on Imaging Sciences, vol. 9, no. 3, pp. 1355-1373, 2016. https://doi.org/10.1137/16M1056936

[29] H. H. Huang and J. Yang, " Affine-transformation invariant clustering models", Journal of Statistical Distributions and Applications, vol. 7, no. 10, pp. 1-24, 2020. https://doi.or g/10.1186 /s40488-020-00111-y 